\title{
Association of Juniperus deppeana (Cupressaceae: Pinales) seeds with Mexican cottontail rabbit (Sylvilagus cunicularius; Leporidae: Lagomorpha) latrines
}

\author{
Ernesto Lezama-Delgado ${ }^{a}$, Pilar Sainos-Paredes ${ }^{a}$, Jorge López-Portillo (1) ${ }^{b}$, \\ Guillermo Angeles ${ }^{b}$, Jordan Golubov ${ }^{c}$ and Armando J. Martínez (1) ${ }^{a}$

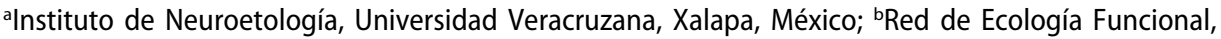 \\ Instituto de Ecología, A.C., Xalapa, México; 'Laboratorio de Ecología, Sistemática y Fisiología Vegetal, \\ Universidad Autónoma Metropolitana-Xochimilco, México City, México
}

\begin{abstract}
Seed aggregation in latrines of rabbits is a little-studied process that may contribute substantially to seed dispersal and survival. We located Juniperus deppeana trees and the latrines used by the endemic Mexican cottontail rabbit Sylvilagus cunicularius within a 1 ha fragment of J. deppeana-dominated forest and evaluated their patterns of aggregation as microhabitats used by cottontail rabbits to consume the J. deppeana galbulus (fleshy cones) or to deposit their pellets with defecated seeds. Based on mean latrine area, we marked a $2 \mathrm{~m} \times 2 \mathrm{~m}$ plot centred on the base of every tree or latrine within the study site. We counted all pellets within each plot and analysed them for the presence of seeds of Juniperus or any other species. We found seeds in $13 \%$ of all pellets, mainly those deposited in the latrines. If seeds are scarified by passing through the intestinal tract, seed germination in latrines may increase the probability of survival and establishment. Thus, the community structure and density could change in time as rabbits are changing the places where they place their latrines.
\end{abstract}

\section{ARTICLE HISTORY}

Received 28 May 2014

Accepted 7 June 2016

\section{KEYWORDS}

Endozoochory; rabbits; lagomorphs; seed aggregation; Juniper galbulus

\section{Introduction}

In plant-disperser interactions, the time and place of seed deposition play critical roles in seedling establishment and regeneration of plant populations (Schupp et al. 2010). Seed dispersal is linked to the disperser's movement patterns and behaviour, which may determine the site and conditions dispersed seeds face, the pattern of seed aggregation, the probability of seedling establishment and plant survival, and, ultimately, species diversity and spatial distribution patterns (Williams et al. 2000; Houseman 2014). For example, birds such as many species in the Turdidae, Sylviidae and Muscicapiade are well-documented seed dispersers (Herrera 1995). Additionally, mammals such as primates (LoGiudice and Ostfeld 2002; Wehncke et al. 2003) and bats (Muscarella and

CONTACT Armando J. Martínez armartinez@uv.mx @Instituto de Neuroetología, Universidad Veracruzana, Av. Luis Castelazo s/n Col. Industrial Animas, 91190 Xalapa, Veracruz, México 
Fleming 2007; Bolívar-Cimé et al. 2015) are known dispersers, but less is known on the role of lagomorphs.

Lagomorphs make a significant contribution to ecological systems by consuming fruits and dispersing seeds in arid and semi-arid environments (Muñoz-Reinoso 1993; Nogales et al. 1995; Izhaki and Ne'eman 1997; Castro et al. 2008), dune systems (Calviño-Cancela 2002, 2004; Pakeman et al. 2002; Dellafiore et al. 2006, 2010; Larrinaga 2010), pasturelands (Malo and Suárez 1995; Malo and Yanes 1999), thickets (Staniforth and Cavers 1977; Cosyns et al. 2005), wetlands (Zedler and Black 1992; Chang et al. 2005), and woodlands and abandoned lands (Schupp et al. 1997a; Escribano-Avila et al. 2012). These studies have highlighted the role of lagomorphs as important seed-dispersal agents in diverse environments in conserved and disturbed landscapes. However, none of these studies related the number of seeds dispersed to different microhabitats and to temporal variations to describe the natural history and behavioural ecology of rabbits.

Lagomorphs are ideal subjects to study the effects of seed aggregation on landscape dynamics because they deposit most of their faecal pellets in fixed sites, called 'latrines' or 'dunghills' (Sneddon 1991; Zollner et al. 1996). The importance of latrines for seed dispersal and establishment needs to be evaluated due to their potential effects on community structure and composition (Pakeman et al. 1999; Verdú et al. 2009).

The Mexican cottontail Sylvilagus cunicularius Waterhouse (Leporidae: Lagomorpha) is endemic to Mexico (Vázquez et al. 2007) and occurs over a wide altitudinal range, from arid lowlands at sea level to temperate highlands at $3500 \mathrm{~m}$ above sea level (asl) (Cervantes et al. 1992). This rabbit inhabits pine and oak-pine forests which includes the fragmented juniper forests along the Mexican Transvolcanic Belt, all with an understory of clumped grasses (Fa et al. 1992). Sylvilagus cunicularius feeds on fruits, young leaves of forbs, shrubs, grasses and cultivated plants, and deposits its pellets mainly in latrines (Cervantes et al. 1992) which are typically placed in open spaces, perhaps as a means to avoid predation. The Mexican cottontail rabbit is sympatric with Sylvilagus floridanus Allen and Romerolagus diazi FerrariPérez, but the pellets from these species can be distinguished with high accuracy based on size, shape and colour (Fa et al. 1992). Junipers are among the few deciduous gymnosperms that develop fleshy cones that function similarly to the fleshy fruits of angiosperms (Herrera 1992). Female cones of Juniperus deppeana Steudel may contain one to three seeds, and the peak fruit production is between December and June (Martínez et al. 2007). When eaten by birds or lagomorphs, the seeds pass through the gut without suffering apparent damage and can thus be dispersed (Adams 1993; Schupp et al. 1997b; Chambers et al. 1999).

In this respect, the goal of this study was to assess the temporal and spatial patterns of Juniperus deppeana seed dispersal by the endemic Mexican rabbit Sylvilagus cunicularius. We hypothesised that more Juniperus deppeana seeds will be found in rabbit latrines when compared to other microhabitats, opening the possibility of latrines contributing to the recruitment of new plants.

\section{Materials and methods}

\section{Study site}

The study site $\left(19^{\circ} 20^{\prime} 4.81^{\prime \prime} \mathrm{N}, 98^{\circ} 21^{\prime} 51.60^{\prime \prime} \mathrm{W} ; 2300 \mathrm{~m}\right.$ asl) was located $14 \mathrm{~km}$ west of the city of Tlaxcala, in east-central Mexico. It is a 10 ha fragment of an original J. deppeana 
forest within a grassland dominated by Muhlenbergia implicata (Kunth) Trinius, Stipa ichu (Ruiz and Pavón) Kunth, Aristida schiedeana Trinius and Ruprecht (Poaceae), and Rhus standleyi F.A. Barkley (Anacardiaceae) (Hudson et al. 2005). This fragment is surrounded by corn fields and forested fragments where Eucalyptus globulus Labillardière was introduced in 1980. The climate is temperate subhumid, with a mean annual rainfall of 800-1000 mm, mainly during the summer months, from June through September (only $5 \%$ of the precipitation falls during winter). Furthermore, the site has a topographic slope of $10^{\circ}$, causing a slight runoff during rains.

\section{Sampling design}

A $100 \mathrm{~m} \times 100 \mathrm{~m}$ plot was randomly selected at the study site and all J. deppeana trees (female, male and juvenile trees) and rabbit latrines were located. The total crown cover of Juniperus within the plot was about $4000 \mathrm{~m}^{2}$. The area of each latrine and of the crown of each juniper was estimated as an ellipse by measuring the longest axis and the axis perpendicular to that. The sampling area of the latrine and under the crown of each juniper tree was standardised with respect to the mean latrine size $\left(\bar{X}=3.3 \pm 0.08 \mathrm{~m}^{2}\right.$, standard error (SE)), rounded up to $4 \mathrm{~m}^{2}$ to have uniform areas to compare. Pellets were found on bare ground and below juniper crowns but were absent from other habitats, such as pasturelands and shrublands. In addition, the numbers of pellets in other habitats are low and the highest concentrations of pellets are located in latrines.

\section{Pellet and seed collection}

A $4 \mathrm{~m}^{2}$ plot was centred on each latrine and a $4 \mathrm{~m}^{2}$ plot was also set below each Juniperus tree by tracing a $1.13 \mathrm{~m}$ radius and the distance at which the sample area was $30 \mathrm{~cm}$ from the trunk of the plant. At the beginning of the sampling period (first week of July 2004), all fresh (recently defecated) pellets within each plot were collected, but the older pellets were left in situ to keep the odor mark of each latrine (Sneddon 1991; Zollner et al. 1996). All fresh pellets (i.e. not older than the sampling period) were collected roughly every 2 months from 15 August 2004 through August 2005. The pellets were counted, collected and stored in paper bags until each one was examined under a stereoscopic microscope to extract the seeds, which were separated by appearance and weighed on a digital scale (ADAM AAA100L, Danbury CT, USA) to the nearest $0.01 \mathrm{mg}$.

\section{Statistical analyses}

We analysed the latrines and trees (female, male and juvenile trees) on a three-dimensional $(x, y, z)$ coordinate system to identify their spatial distribution (where $x$ and $y$ indicate the Cartesian location in metres inside the $100 \mathrm{~m} \times 100 \mathrm{~m}$ study area, and $\mathrm{z}$ is the area of latrines or the canopy of each juniper). Data were tested using RookCase spatial autocorrelation analysis with the equations for global Moran's / join counts with Queen's adjacency coefficient of contiguity between latrines and trees (four cardinal plus four diagonal neighbours). This is a test to explore the spatial association between latrines and plant canopies. The significance was assessed using Moran's Index using a 
Monte Carlo test with 500 permutations (Sawada 1999). No autocorrelation would indicate that latrine location distribution is independent of tree gender and size (Legendre 1993).

The density of pellets and number seeds per pellet were analysed with repeated measures analysis of variance (ANOVA) with microhabitat (latrine or tree) as a fixed factor and time as the repeated measure. The data were previously tested for homogeneity of variances and normality, and rank-transformed when necessary (Conover and Iman 1981). All analyses were made with Statistica 7 (Stat Soft, Inc. Tulsa, USA).

\section{Results}

\section{Spatial association}

There was no spatial association between the 105 latrines, which occupied $347 \mathrm{~m}^{2}$, and the $328 \mathrm{~J}$. deppeana trees, which occupied $4000 \mathrm{~m}^{2}(\mathrm{I}=0.008, P=0.35$; Table 1$)$, indicating a random distribution: therefore, rabbit latrines are not under the canopies of the plants. The mean distance between latrines and junipers was $30 \pm 1.8 \mathrm{~m}$ (standard deviation (SD)), and the mean crown size of junipers was $12 \pm 1.6 \mathrm{~m}^{2}(\mathrm{SD})$.

\section{Pellet deposition}

Only one rabbit species (Sylvilagus cunicularius) was registered at the study site, as indicated by the homogeneous size and appearance of the pellets (Fa et al. 1992). There were no significant differences between types of trees in the density of deposited pellets and seeds $\left(F_{2,431}=1.2, P>0.05\right.$, and $\left.F_{2,431}=1.6, P>0.05\right)$. There was a significantly higher density of pellets in latrines than under the juniper trees $\left(F_{1,431}=362, P<0.0001\right)$. In addition, there was a significant effect of time $\left(F_{4,1724}=26\right.$, $P<0.0001)$ and a significant microhabitat $\times$ time interaction $\left(F_{4,1724}=16, P<0.0001\right)$, with the most pellets counted in September 2004 and April 2005 in latrines, while seed counts beneath trees were relatively uniform throughout the study (Figure 1(a)).

\section{Seed deposition}

There were seeds in $14 \%$ of the 25,649 S. cunicularius pellets we examined; $13 \%$ had J. deppeana seeds, $1 \%$ Opuntia tomentosa var. tomentosa seeds and $0.1 \%$ had unidentified Solanaceae seeds. There were pellets with seeds in all latrines and in all plots under the junipers.

Table 1. Moran's I and normal Z-values for the autocorrelation by join counts (Queen's adjacency) between latrines $(I)$ and female, male and juvenile Juniperus deppeana trees $(t)$. Values in parentheses indicate the expected value of join counts for each category. $P>0.05$ in all cases.

\begin{tabular}{lcccccr}
\hline Association & $t /$ joins & $Z$ & $t t$ joins & $z$ & $\|$ joins & $Z$ \\
\hline Latrine - female & $5(63)$ & -1.4 & $119(162)$ & -0.87 & $107(6)$ & 9 \\
Latrine - male & $6(67)$ & -1.35 & $171(211)$ & -0.79 & $107(5)$ & 10 \\
Latrine - juvenile & $2(57)$ & -1.68 & $48(92)$ & -1 & $107(9)$ & 7 \\
\hline
\end{tabular}



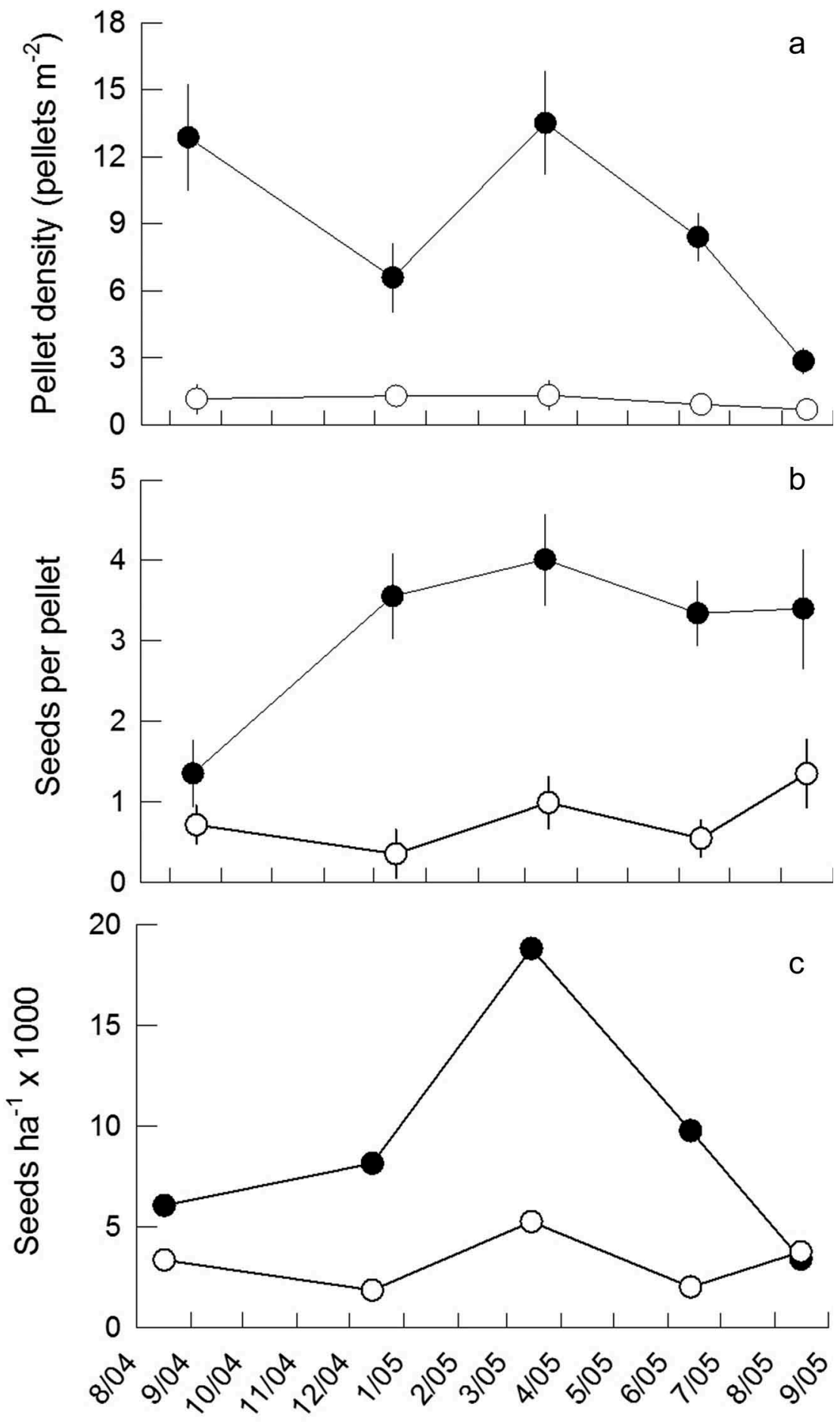

\section{Month/year}

Figure 1. (a) Density of Sylvilagus cunicularius pellets; (b) number of Juniperus deppeana seeds per pellet; and (c) number of seeds in the hectare under study deposited under trees (empty symbols) or in latrines (filled symbols) from August 2004 through August 2005. In (a) and (b), vertical bars indicate one SE. 
The repeated measures ANOVA indicated a significant effect of microhabitat $\left(F_{1,431}=188.1, P<0.0001\right)$, time of collection $\left(F_{4,1724}=10.1, P<0.0001\right)$, and microhabitat $\times$ time interaction $\left(F_{4,1724}=11.3, P<0.0001\right)$. The Fisher's least significant difference multiple comparison procedure indicates there were more seeds in pellets from latrines than in pellets below the trees, except in September of 2004 (Figure 1(b)). Multiplying the density of pellets by the number of seeds per pellet and by the area covered by latrines or tree canopies, we found that seeds from latrines accounted for 47.5 to $83 \%$ of the total number of seeds per hectare; numbers of seeds were similar in the two microhabitats in September, but in March many more seeds were found in latrines (Figure 1(c)).

\section{Discussion}

We found that $S$. cunicularius deposited a greater density of seeds in latrines than below the canopy of J. deppeana, and that there are spatiotemporal differences in the number of seeds deposited even considering the relative cover of both habitats, suggesting that rabbits play a very clear role as dispersers of juniper seeds. The patchy deposition of seed-containing pellets in latrines suggests that recruitment of $J$. deppeana individuals could benefit from latrine-use behaviour. However, we only address a small part of the recruitment process and do not evaluate seedling recruitment and survival. Further work is necessary. The proportion of pellets of the Mexican cottontail rabbit Sylvilagus cunicularius with seeds (14\%) was higher than the $3 \%$ of pellets containing Retama sphaerocarpa Boissier seeds reported for Oryctolagus cuniculus Linnaeus (Malo and Yanes 1999), or the $7 \%$ of $O$. cuniculus pellets having seeds belonging to several shrub species (Malo et al. 2000), but lower than the proportions found in other species of arid zones, which range from 43 to 64\% (Nogales et al. 1995; Izhaki and Ne'eman 1997; Santos et al. 1999). Such differences could be related to the variability of fruit production from year to year.

Our results further suggest that the high density of seed dispersal by rabbits to latrines may have influence on the population dynamics, structure and colonisation of plant communities, as proposed for grassland (Malo et al. 1995; Malo and Suárez 1995; Pakeman et al. 1999) and dune (Dellafiore et al. 2010) ecosystems. There is also a possibility of extensive secondary dispersal if rainfall washes the pellets away from the latrines (Nogales et al. 1995), especially in highly sloped sites such as in our own study site.

There is a clear temporal pattern in seed deposition in latrines, which seems linked to the period when most Juniperus female cones are available, which is from June to December (Martínez et al. 2007). These months are characterised by heavy rainfall and water runoff, likely resulting in the secondary movement of many pellets and seeds away from the latrines. This probably influences $J$. deppeana recruitment of seedlings in or downslope of the latrines, as we have indeed observed in the field. Also, seed germination and sapling survival and growth may be enhanced, because latrines may provide nutrients, organic matter and humidity that ameliorate the conditions of formerly bare soils (Willott et al. 2000; Verdú et al. 2009). The concentration of seeds could increase their vulnerability to predation (LoGiudice and Ostfeld 2002) 
or, contrariwise, increase the probability that a few of them may germinate to become seedlings.

In rabbits, the intestinal retention period may be between 20 and 30 hours (Illius and Gordon 1992; Cosyns et al. 2005), allowing sufficient time for seeds to be dispersed long distances (up to $150 \mathrm{~m}$ ) from the parent plant (Cosyns et al. 2005). While the home range of S. cunicularius is unknown, estimates for other Sylvilagus species of similar body size suggest it is likely between 0.2 and 7.7 ha (Bond et al. 2001). Due to their pelletdepositing behaviour and subsequent dispersal, rabbits are in fact moving the seeds away from the parent plants (Calviño-Cancela 2002).

We did not find seeds or cones in bird droppings or any other animal faeces, suggesting that rabbits are the major dispersers. In this sense it has been reported that O. cuniculus disperses $14 \%$ of the seeds of Corema album (Linnaeus) D.Don ex Steudel, which is relatively low compared with the $40 \%$ dispersed by the blackbird Turdus merula Linnaeus (Passeriformes: Turdidae) (Calviño-Cancela 2002). Hence, rabbits may be important dispersal agents, especially in areas with sparse plant cover (Santos et al. 1999), and abandoned agricultural fields (Escribano-Avila et al. 2012), or when there is a lack of other dispersers. In our study system, rabbits are feeding on the fruits of J. deppeana, which are hard, fibrous and brown, characteristics suggested to be associated with mammal rather than bird dispersal of juniper seeds (Chambers et al. 1999). In addition, the fruits fall to the ground beneath the trees. Therefore, it is expected that dispersal will be predominantly by mammals such as lagomorphs and the ring-tailed cat Bassariscus astutus Lichtenstein (Carnivora: Procyonidae). Latrine formation and distribution in S. cunicularius can thus modulate spatiotemporal differences in the density of deposited seeds, but field experiments and observations should be done to test whether this increases the potential of J. deppeana to colonise new microhabitats.

\section{Acknowledgements}

We thank F. Aureli and M. Calviño-Cancela for comments on an earlier draft, and E.W. Schupp and another, anonymous reviewer for many suggestions and constructive criticism. This work was supported by the projects UVER-PTC-223 and PFA C-703/2013 to AJM, as well as doctoral scholarships 218107 (ELD) and 260164 (PSP).

\section{Disclosure statement}

No potential conflict of interest was reported by the authors.

\section{ORCID}

Jorge López-Portillo (1) http://orcid.org/0000-0002-6827-3297

Armando J. Martínez (D) http://orcid.org/0000-0002-1248-2516 


\section{References}

Adams RP. 1993. Juniperus. In: Morin NR, editor. Flora of North America North of Mexico. Vol 2, pteridophytes and gymnosperms. New York (NY): Oxford University Press; p. 412-420.

Bolívar-Cimé B, Laborde J, Sosa VJ. 2015. Effects of landscape matrix type, patch quality and seasonality on the diet of frugivorous bats in tropical semi-deciduous forest. Wildl Res. 41:454-464.

Bond BT, Leopold BD, Burger LW, Godwin KD. 2001. Movements and home range dynamics of cottontail rabbits in Mississippi. J Wildl Manage. 65:1004-1013.

Calviño-Cancela M. 2002. Spatial patterns of seed dispersal and seedling recruitment in Corema album (Empetraceae): the importance of unspecialized dispersers for regeneration. J Ecol. 90:775-784.

Calviño-Cancela M. 2004. Ingestion and dispersal: direct and indirect effects of frugivores on seed viability and germination of Corema album (Empetraceae). Acta Oecol. 26:55-64.

Castro SA, Bozinovic F, Jaksic FM. 2008. Ecological efficiency and legitimacy in seed dispersal of an endemic shrub (Lithrea caustica) by the European rabbit (Oryctolagus cuniculus) in central Chile. J Arid Environ. 72:1164-1173.

Cervantes FA, Lorenzo C, Vargas J, Holmes T. 1992. Sylvilagus cunicularius. Mamm Sci. 412:1-4.

Chambers JC, Vander Wall SB, Schupp EW. 1999. Seed and seedling ecology of piñon and juniper species in the pygmy woodlands of Western North America. Bot Rev. 65:1-38.

Chang ER, Zozaya EL, Kuijper DP, Bakker JP. 2005. Seed dispersal by small herbivores and tidal water: are they important filters in the assembly of salt marsh communities? Funct Ecol. 19:665-673.

Conover WJ, Iman RL. 1981. Rank transformations as a bridge between parametric and nonparametric statistics. Am Stat. 35:124-129.

Cosyns E, Delporte A, Lens L, Hoffmann M. 2005. Germination success of temperate grassland species after passage through ungulate and rabbit guts. J Ecol. 93:353-361.

Dellafiore CM, Gallego Fernández JB, Muñoz Vallés S. 2010. The rabbit (Oryctolagus cuniculus) as a seed disperser in a coastal dune system. Plant Ecol. 206:251-261.

Dellafiore CM, Muños Vallés S, Gallego Fernández JB. 2006. Rabbits (Oryctolagus cuniculus) as dispersers of Retama monosperma seeds in a coastal dune system. Ecoscience. 13:5-10.

Escribano-Avila G, Sanz-Pérez V, Pías B, Virgós E, Escudero A, Valladares F. 2012. Colonization of abandoned land by Juniperus thurifera is mediated by the interaction of a diverse dispersal assemblage and environmental heterogeneity. PLOS ONE. 7:e46993.

Fa JE, Romero FJ, Lopez-Paniagua J. 1992. Habitat use by parapatric rabbits in a Mexican highaltitude grassland system. J Appl Ecol. 29:357-370.

Herrera CM. 1992. Interspecific variation in fruit shape: allometry, phylogeny, and adaptation to dispersal agents. Ecology. 73:1832-1841.

Herrera CM. 1995. Plant-vertebrate seed dispersal systems in the Mediterranean: ecological, evolutionary and historical determinants. Annu Rev Ecol Syst. 26:705-727.

Houseman GR. 2014. Aggregated seed arrival alters plant diversity in grassland communities. J Plant Ecol. 7:51-58.

Hudson R, Rodríguez-Martínez L, Distel H, Cordero C, Altbäcker V, Martínez-Gómez M. 2005. A comparison between vegetation and diet records from the wet and dry season in the cottontail rabbit Sylvilagus floridanus at Ixtacuixtla, central Mexico. Acta Theriol. 50:377-389.

Illius AW, Gordon IJ. 1992. Modelling the nutritional ecology of ungulate herbivores: evolution of body size and competitive interactions. Oecologia. 89:428-434.

Izhaki I, Ne'eman G. 1997. Hares (Lepus spp.) as seed dispersers of Retama raetam (Fabaceae) in a sandy landscape. J Arid Environ. 37:343-354.

Larrinaga AR. 2010. Rabbits (Oryctolagus cuniculus) select small seeds when feeding on the fruits of Corema album. Ecol Res. 25:245-249.

Legendre P. 1993. Spatial autocorrelation: trouble or new paradigm? Ecology. 74:1659-1673.

LoGiudice K, Ostfeld RS. 2002. Interactions between mammals and trees: predation on mammaldispersed seeds and the effect of ambient food. Oecologia. 130:420-425.

Malo JE, Jiménez B, Suárez F. 1995. Seed bank build-up in small disturbances in a Mediterranean pasture: the contribution of endozoochorous dispersal by rabbits. Ecography. 18:73-82. 
Malo JE, Jiménez B, Suárez F. 2000. Herbivore dunging and endozoochorous seed deposition in a Mediterranean dehesa. J Range Manage. 53:322-328.

Malo JE, Suárez F. 1995. Herbivorous mammals as seed dispersers in a Mediterranean dehesa. Oecologia. 104:246-255.

Malo JE, Yanes M. 1999. ¿Endozoocoria o depredación? La ingestión de legumbres de Retama sphaerocarpa por el conejo (Oryctolagus cuniculus). In: Actas de la XXXIX Reunión Científica de la Sociedad Española para el Estudio de los Pastos; Almería, España; p. 93-98.

Martínez AJ, Sainos PP, Lezama DE, Angeles G. 2007. El tamaño sí importa: los frutos grandes de Juniperus deppeana Steud. (sabino) son más susceptibles a depredación por insectos. Madera y Bosques. 13:65-81.

Muñoz-Reinoso JC. 1993. Consumo de gálbulos de sabina (Juniperus phenica ssp. turbinata Guss 1981) y dispersión de semillas por el conejo (Oryctolagus cuniculus L.) en el Parque Nacional de Doñana. Doñana Acta Vert. 20:49-58.

Muscarella R, Fleming TH. 2007. The role of frugivorous bats in tropical forest succession. Biol Rev. 82:573-590.

Nogales M, Valido A, Medina FA. 1995. Frugivory of Plocama pendula (Rubiaceae) by the rabbit (Oryctolagus cuniculus) in xerophytic zones of Tenerife (Canary Islands). Acta Oecol. 16:585-591.

Pakeman RJ, Digneffe G, Small JL. 2002. Ecological correlates of endozoochory by herbivores. Funct Ecol. 16:296-304.

Pakeman RJ, Engelen J, Attwood JP. 1999. Rabbit endozoochory and seed bank build up in an acidic grassland. Plant Ecol. 145:83-90.

Santos T, Telleria JL, Virgós E. 1999. Dispersal of Spanish juniper Juniperus thurifera by birds and mammals in a fragmented landscape. Ecography. 22:193-204.

Sawada M. 1999. Rookcase: an Excel 97/2000 visual basic (VB) add-in for exploring global and local spatial autocorrelation. Bull Ecol Soc Am. 80:231-234.

Schupp EW, Gómez JM, Jiménez JE, Fuentes M. 1997a. Dispersal of Juniperus occidentalis (western juniper) seeds by frugivorous mammals on Juniper Mountain, Southeastern Oregon. Great Basin Nat. 57:74-78.

Schupp EW, Heaton HJ, Gómez JM. 1997b. Lagomorphs and the dispersal of seeds into communities dominated by exotic annual weeds. Great Basin Nat. 57:253-258.

Schupp EW, Jordano P, Gómez JM. 2010. Seed dispersal effectiveness revisited: a conceptual review. New Phytol. 188:333-353.

Sneddon IA. 1991. Latrine Use by the European Rabbit (Oryctolagus cuniculus). J Mammal. 72:769775.

Staniforth RJ, Cavers PB. 1977. The importance of cottontail rabbits in the dispersal of Polygonum spp. J Appl Ecol. 14:261-267.

Vázquez J, Martínez AJ, Hudson R, Rodríguez-Martínez L, Martínez-Gómez M. 2007. Seasonal reproduction in Mexican cottontail rabbits Sylvilagus cunicularius in La Malinche National Park, central Mexico. Acta Theriol. 52:361-369.

Verdú JR, Numa C, Lobo JM, Martínez-Azorín M, Galante E. 2009. Interactions between rabbits and dung beetles influence the establishment of Erodium praecox. J Arid Environ. 73:713-718.

Wehncke EV, Hubbell SP, Foster RB, Dalling JW. 2003. Seed dispersal patterns produced by whitefaced monkeys: implications for the dispersal limitation of Neotropical tree species. J Ecol. 91:677-685.

Williams PA, Karl BJ, Bannister P, Lee WG. 2000. Small mammals as potential seed dispersers in New Zealand. Austral J Ecol. 25:523-532.

Willott SJ, Miller AJ, Incoll LD, Compton SG. 2000. The contribution of rabbits (Oryctolagus cuniculus L.) to soil fertility in semi-arid Spain. Biol Fertil Soils. 31:379-384.

Zedler PH, Black C. 1992. Seed Dispersal by a Generalized Herbivore: rabbits as Dispersal Vectors in a Semiarid California Vernal Pool Landscape. Amer Midland Nat. 128:1-10.

Zollner PA, Smith WP, Brennan LA. 1996. Characteristics and adaptive significance of latrines of swamp rabbits (Sylvilagus aquaticus). J Mammal. 77:1049-1058. 